Article

\title{
Modeling Soil and Woody Vegetation in the Senegalese Sahel in the Context of Environmental Change
}

\author{
Martin Brandt ${ }^{1, *}$, Tobias Grau ${ }^{2}$, Cheikh Mbow ${ }^{3,4}$ and Cyrus Samimi ${ }^{1,5}$ \\ ${ }^{1}$ Institute of Geography, University of Bayreuth, 95440 Bayreuth, Germany; \\ E-Mail: cyrus.samimi@uni-bayreuth.de \\ ${ }^{2}$ Institute of Geography and Regional Research, University of Vienna, 1090 Vienna, Austria; \\ E-Mail: tobias_grau@arcor.de \\ ${ }^{3}$ Forestry-ICRAF (World Agroforestry Center), 00100 Nairobi, Kenya \\ ${ }^{4}$ Institut des Sciences de l'Environnement, Université Cheikh Anta Diop, BP 5005 Dakar, Senegal; \\ E-Mail: c.mbow@cgiar.org \\ ${ }^{5}$ Bayreuth Center of Ecology and Environmental Research (BayCEER), University of Bayreuth, \\ 95440 Bayreuth, Germany \\ * Author to whom correspondence should be addressed; E-Mail: martin_brandt@gmx.net; \\ Tel.: +49-1769-8269-998.
}

Received: 7 March 2014; in revised form: 2 July 2014 / Accepted: 9 July 2014 /

Published: 18 July 2014

\begin{abstract}
Climatic stress and anthropogenic disturbances have caused significant environmental changes in the Sahel. In this context, the importance of soil is often underrepresented. Thus, we analyze and discuss the interdependency of soil and vegetation by classifying soil types and its woody cover for a region in the Senegalese Ferlo. Clustering of 28 soil parameters led to four soil types which correspond with local Wolof denotations: Dek, Bowel, Dior and Bardial. The soil types were confirmed by a Non-metric Multidimensional-Scaling (NMDS) ordination and extrapolated via a Random Forest classifier using six significant variables derived from Landsat imagery and a digital elevation model (out-of-bag error rate: 7.3\%). In addition, canopy cover was modeled using Landsat and a Reduced-Major-Axis (RMA) regression $\left(R^{2}=0.81\right)$. A woody vegetation survey showed that every soil type has its own species composition. However, 29\% of Bowel regions are deforested (i.e., degraded) and interviews revealed extensive environmental changes and a strong decline and local extinction of woody species. The differences between the soil types are significant, showing that vegetation changes (i.e., degradation and greening), resilience to climatic stress and human activities largely depend on soil properties. We highlight that spatial
\end{abstract}


heterogeneity is an important aspect when dealing with environmental changes in the Sahel, and local knowledge can be well used to classify spatial units by means of public Earth observation data.

Keywords: Sahel; degradation; environmental change; soil; NMDS; Random Forest; Senegal; Wolof; canopy cover; Ferlo

\section{Introduction}

The Sahel zone has undergone major environmental changes in the past 50 years (e.g, [1-3]). Severe droughts, a considerable drop in annual rainfall (e.g, [4]) and increasing human activities have had massive impact on Sahelian ecosystems. Natural vegetation is rapidly declining and a shift in woody species composition is observed, adapting to a more arid climate [5-7].

Vegetation changes, degradation and re-greening in the Sahel have long been researched and discussed (e.g, $[5,8-10])$ and studies agree that woody vegetation structure plays a decisive role as an indicator for ecosystem health. In addition, trees and shrubs are fundamental for people's daily life [11], particularly for food and mostly fodder in a short lasting herbaceous cover. Although rainfall and human management are prominent factors controlling tree and shrub growth, woody cover, species structure as well as its resilience mainly depend on morpho-pedological site conditions and thus primarily on soil properties [12]. For better understanding of past and ongoing processes, detailed classifications of soil and vegetation units are required.

Vegetation and soil studies in the Senegalese Sahel date back to 1965, and offer valuable information from times before the severe droughts in the 1970s and 1980s [13-15]. Stancioff et al. [16] published maps of Senegal's geology, soil, morpho-pedology, vegetation and the agricultural suitability based on the assessments from 1965, field data and remote sensing imagery. Tappan et al. [1] divided Senegal in ecoregions partly based on Stancioff's maps. Several studies regarding woody vegetation change and degradation in the Ferlo exist. Vincke et al. [8] detected human and drought induced degradation and highlighted the importance of soil and topographic elements for species composition and tree density. Miehe et al. [17] conducted a long term study in Widou Thiengoly, monitoring vegetation in fenced and unfenced sites over 27 years. They observed degradation and species impoverishment induced by livestock grazing. Additionally, several reports by the CSE (Centre de Suivi Ecologique) are available including land-cover maps of the Ferlo as well as degradation assessments (e.g., [18]). Other international projects are located in Senegal's Sahel as well (e.g., LADA—Land Degradation Assessment in Drylands or ROSELT [19]).

To link vegetation changes to morpho-pedological site conditions, the present study suggests a statistical methodology to model soil types over an area in the Senegalese Ferlo by means of remote sensing products. Soils are classified according to their names in the local language (Wolof). Therefore, the objective of this study is to demonstrate that spatial units derived from local knowledge can be modeled and used to gain a sound scientific soil classification which (a) forms a basis for discussions on 
environmental change and vulnerability and (b) offers information on the predominant woody vegetation and agricultural suitability.

\section{Materials and Methods}

\subsection{Study Area}

The study area is located in the Senegalese Ferlo around the city of Linguère (Figure 1). Mean annual rainfall is $450 \mathrm{~mm}$ with a high inter- and intra-annual variability and a steep north-south gradient. Severe droughts in the 1970s and 1980s combined with a remarkable decrease in annual rainfall are observed at the Linguère weather-station [20]. Due to this decline in precipitation and the presence of protected areas, only $15 \%$ of the study area are currently cultivated with millet and groundnut by Wolof farmers who live in larger villages around Linguère and Dahra. Semi-nomadic Fulani who practice animal husbandry with cattle, goats and sheep, settle in the region and make up $85 \%$ of the population in the Ferlo. Thus, the study area is known as a Fulani/Pular silvo-pastoral zone [21,22].

Figure 1. Position of the study area. The 84 training sites are located inside the circle around Linguère. For a detailed close up of the study area with high resolution imagery, we refer to Brandt et al. [22].

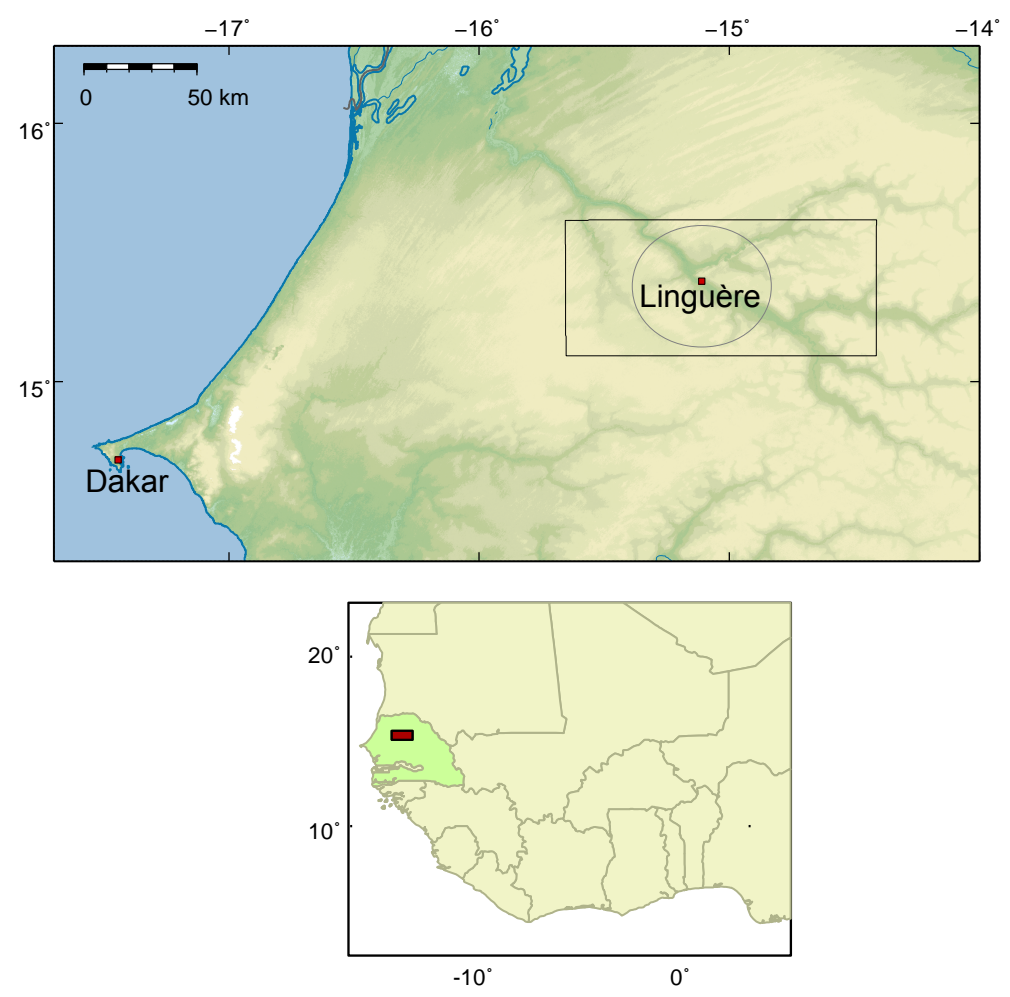

Tappan et al. [1] divided the study area in 3 ecoregions: the (a) northern and (b) southern sandy regions with aeolian sands and the (c) ferruginous pastoral region in the east, formed by a sandstone plateau which is dissected by ancient valleys. Within these ecoregions, we use four spatial units/soil denotations used by the local population. Applying and understanding classifications based on local knowledge are important tasks and they are rarely applied in science [23]. The classes/soil types are 
summarized in Table 1 and illustrated in Figure 2 (1) Dek; (2) Bowel; (3) Dior; and (4) Bardial. Small depressions with gray and clayey hydromorphic soils are spread throughout the Ferlo region and are called Xour and their clayey soils (1) Dek in Wolof. These Vertisols are formed by colluvial and alluvial sediments and characterized by standing water which often remains several months after the rainy season. Beneath the shallow clays with hydromorphic characteristics, sands and gravel form the basis of the soils. Woody vegetation is manifold and species composition and its density depend on the soil's grain size distribution. For herders and their livestock, these sites are a valuable source for drinking water and fodder in form of leaves. Different perceptions of the terms Xour and Dek exist. In this study, heavy clayey soils with standing water are considered as Dek.

Table 1. Pedological terms and units used in this study.

\begin{tabular}{ccccc}
\hline Wolof Soil & Wolof Morphological Unit & Soil Characteristics & Soil Type & Usage \\
\hline (1) Dek & Xour & clayey depression & Vertisol & pasture, drinking water \\
(2) Bowel & All & ferruginous/stony & Regosol & pasture \\
(3) Dior & Tound & sandy dune soil & Arenosol & cropping, pasture \\
(4) Bardial & Tound & heavy sandy dune soil & Arenosol & cropping, pasture \\
\hline
\end{tabular}

Figure 2. (1) A flooded Xour with Dek soils and large Acacia tomentosa trees; (2) Bowel region with exposed laterite; (3) a Dior peanut fallow with Combretum glutinosum shrubs; (4) a Bardial cultivated with millet and Balanites aegyptiaca trees. Also an Acacia raddiana can be seen here. Photos are taken in March (4) and September (1-3) 2012.

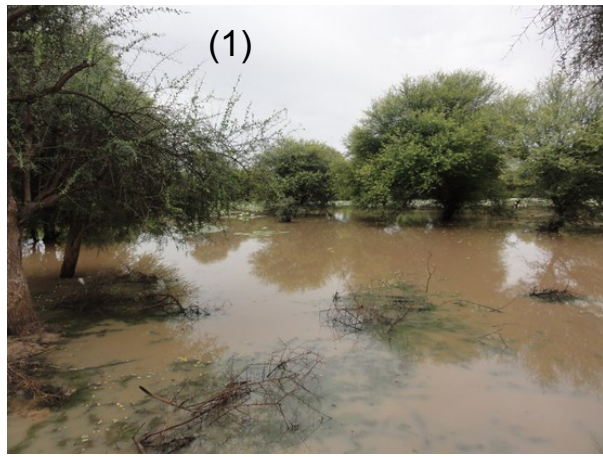

(3)

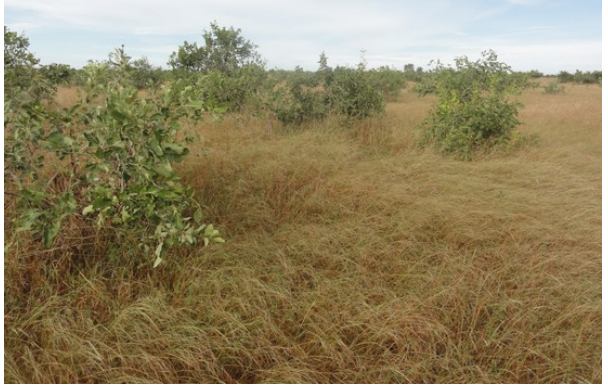

(2)

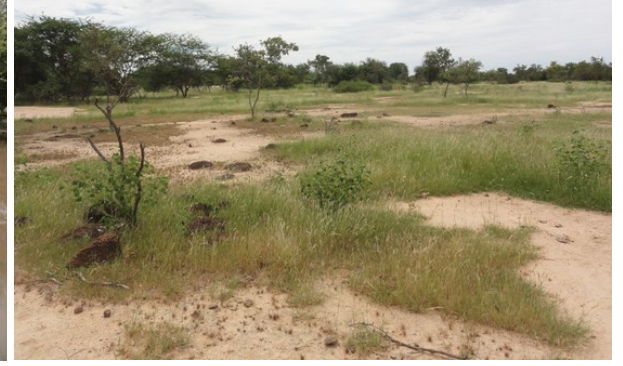

(4)

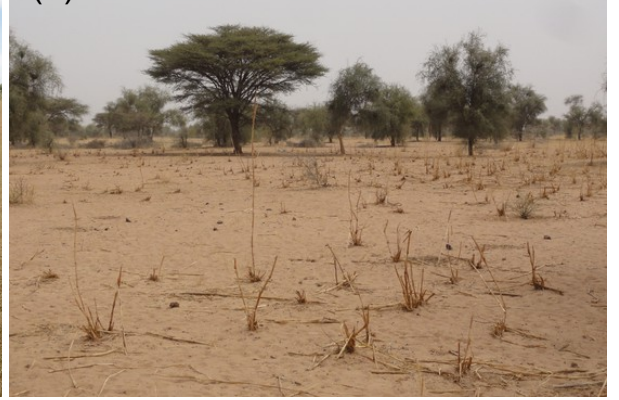

The eastern parts of the Ferlo are formed by clayey formations on the continental shelf of the Oligo-, Mio- or Pliocene [14]. These Regosols are stony, shallow, poorly developed and laterite is often visible at the surface. This results in a great number of small unvegetated spots throughout the whole region 
which are called Karré in Wolof. Depressions with more loamy soils are widespread within this zone and standing water during the rainy season is common. Typical vegetation of this area is a shrub savanna mainly used for livestock grazing. Soils are susceptible to trampling, compaction and erosion through water and wind, thus degradation is apparent at many sites [16]. Large parts of the lateritic Ferlo are declared as protected area and agriculture is prohibited. In Wolof, the laterite soils are often called souf bou khonk (meaning reddish soil). However, as no clear and short expression exists, we use the Fulani (also used by Wolof) name for laterite: (2) Bowel (also spelled Bowal and Bowe).

The most predominant soil is a tropical soil developed on aeolian dune formations (Tound in Wolof) and is named (3) Dior in Wolof (also spelled joor). Dior soils are Arenosols with a good infiltration rate and a clay content not more than 6\% [16]. Despite their moderate fertility, Dior have a great importance for cultivation of crops and as grazing land [14]. Ndiaye [24] further subdivides the Arenosols in (4) Bardial with differences in predominant vegetation and suitability for crops. According to Ndiaye [24], Diors were cultivated with groundnuts, beans, millet and manioc until the droughts in the 1970s. However, in recent times, groundnuts and beans are mainly cultivated. Bardial soils are characterized as more heavy, unsuited for groundnut and exclusively cultivated with millet.

\subsection{Data and Methodology}

A detailed soil map derived from field work, multivariate statistics and remote sensing forms the basis of this study. Soil types, their properties and spatial dimensions as well as the occurring woody species growing on these soils were studied. Woody vegetation surveys and a modeled canopy cover map were grouped and explained according to the soil map. Interviews with the local population supported by existing literature were the basis for a discussion on environmental changes, climatic and erosion vulnerability for each soil type.

\subsubsection{Fieldwork}

Fieldwork was carried out during the dry (February, March) and the rainy season (September) of 2012 and the dry season of 2011 (February). In a first step, interviews with the local population were conducted in 6 Wolof villages and 3 Fulani settlements around Linguère to ascertain the local denotation of soil units as well as their agricultural use. Furthermore, information on the predominant woody vegetation growing on each unit was collected. This implied species abundance, its change over time and its use in people's daily life. Interviews were semi-structured with individuals, groups and key informants. More information on interview techniques are provided in Brandt et al. [2]. In the dry season 2012, vegetation and soil parameters on 84 representative and equally distributed test sites ( 2 ha each) were surveyed in the field. The sites were selected to represent all zones in existing soil- and vegetation-maps $[15,16]$. All individuals of trees and shrubs along randomly chosen line transects $(200 \mathrm{~m})$ across the plots were identified in accordance with Maydell [11] and documented according to Herrick et al. [25]. Altogether, 2205 individuals of 24 tree and shrub species were surveyed within the 84 plots. Woody vegetation was differentiated in trees higher than $4 \mathrm{~m}$ and shrubs (including small trees) smaller than $4 \mathrm{~m}$. This threshold was chosen to obtain comparable data to previous studies. Height, circumference (breast height), crown diameter, percentage of green leaves and canopy coverage for each tree $>4 \mathrm{~m}$ were determined. Using 
high resolution imagery (RapidEye from 27 December 2010; see Brandt et al. [2]), trees and large shrubs (mostly $>4 \mathrm{~m}$ ) were manually counted on-screen for each 2 ha plot and validated by the field data of the transect line which crosses the plot. The total amount was divided by 2 to obtain the unit tree per hectare.

Finally, soil durability and degradation occurrence were noted according to [26]. Within the same plots, mixed soil samples and undisturbed samples were taken within the upper $20 \mathrm{~cm}$ (for sampling technique see $[27,28])$. The dried mixed samples were transported to a soil laboratory. Soil density and maximum water holding capacity (WCmax) were analyzed in-situ with undisturbed samples [27,28]. Additionally, soil stability was determined in accordance with Herrick et al. [25] and rated between 3 and 8 [29]).

\subsubsection{Laboratory Analysis}

The following soil parameters of all 84 mixed samples were analyzed in a laboratory: $\mathrm{pH}$-value $\left(\mathrm{H}_{2} \mathrm{O}\right)$, electrical conductivity [30], grain size distribution (fine-sand, medium-sand and coarse-sand, clay, silt), $\mathrm{NO}^{3-}, \mathrm{NH}^{4+}, \mathrm{PO}_{4}{ }^{3-}, \mathrm{C} / \mathrm{N}, \mathrm{C}, \mathrm{N}, \mathrm{S}, \mathrm{H}^{+}$, potential cation exchange capacity (CECpot) $\left(\mathrm{Ca}^{2+}, \mathrm{Mg}^{2+}\right.$, $\mathrm{Na}^{+}, \mathrm{K}^{+}, \mathrm{Al}^{3+}, \mathrm{Fe}^{3+}$ ) and base saturation (BS) [28]. For information on techniques and equipment, see [27,28,30]. Available field capacity (FC) was estimated [27]. All parameters are listed in Table A1.

\subsubsection{Statistics and Remote Sensing}

To predict field data from test sites to the entire study area, a relation between field data and remote sensing products was obtained using two different statistical models, established to fit the needs of two different applications: (1) as conventional classification methods (e.g., maximum likelihood) are not suited for dealing with geographical data such as rainfall or a Digital Elevation Model (DEM) [31], Random Forest was chosen as a classifier to extrapolate local soil types over the study area. Therefore, the soil samples were grouped to soil types and a variety of predicting variables identified; (2) To model canopy cover at a continuous scale from $0 \%$ to $100 \%$, a relation between one explaining variable and the test sites was established using a simple and robust regression method (Reduced Major Axis-RMA). Cloud-free multi-spectral Landsat TM (Thematic Mapper) scenes were acquired and converted to reflectance values using a FLAASH (Fast Line-of-sight Atmospheric Analysis of Hypercubes) atmospheric correction. Multi-temporal imagery was averaged covering a time-frame of 10 years. This eliminated seasonal and atmospheric fluctuations which are common in this area with huge rainfall variability. Furthermore, influences of crop rotations and burned areas were minimized by calculating mean values. Despite the drawback of vegetation change over this period which may influence single pixels, averaging the scenes over this time period has proven to deliver best results for both models.

Model Soil Types

1. Group Soil Samples Soil types can often be distinguished by color, texture, predominant vegetation and agricultural use in the field. Local people confirmed this; however, a clear distinction was not always easy. To obtain an appropriate scientific classification based on physical and chemical soil properties, all 28 soil parameters (a listing can be found in Table A1) were used as input attributes for 
a clustering process using the Ward-algorithm and euclidean distance [32]. An ordination (Non-metric Multidimensional Scaling-NMDS) with 2 dimensions and a stres-value of $9.13 \%$ was then calculated using all 28 soil parameters. The NMDS is a very robust ordination, well suited for ordinally scaled and intercorrelated data [33,34]. As the 84 plots were grouped regarding their similarities, the NMDS was able to approve results from the clustering [29].

2. Identify Significant Remote Sensing Parameters As the final step is the area-wide extrapolation of soil types via remote sensing parameters, a variety of variables were fitted over the 2-dimensional space of the NMDS to identify significant relationships between grouped soil sites and remotely sensed raster values. Polygons were drawn over each of the 84 sites and averaged raster values underlying the polygons were extracted. In this way, a DEM derived from SRTM data offered the altitude in $\mathrm{m}$ a.s.l., TRMM (Tropical Rainfall Measurement Mission) rainfall data [35] provided the mean annual rainfall in mm (1998-2010), and the latitude and longitude gave the geographical position of each site. Landsat TM data covers 4 dates over 10 years (24 June 2000; 29 May 2002; 19 May 2007; 12 June 2010). Each band was averaged pixel-wise using the 4 dates. The acquisition dates of the satellite images were during the late dry season in order to minimize the effects of photosynthetic active vegetation and to maximize reflectance values of soil properties. Moreover, at this time almost no grass and crop residues are left covering the ground. As dry bare soil reflects soil parameters best at wavelengths higher than $1.4 \mu \mathrm{m}$ [36], band $5(1.55-1.75 \mu \mathrm{m})$ and $7(2.08-2.35 \mu \mathrm{m})$ were integrated into the NMDS. Band 2 $(0.53-0.61 \mu \mathrm{m})$ added supplementary information on bare soil. The NDVI (Normalized Difference Vegetation Index) as a measurement for green vegetation [36], and the brightness coefficient of a Tasseled Cap (TC) transformation [37] as an additional parameter for soil reflectance, were also incorporated. A listing of all variables can be found in Table A2.

3. Extrapolate with Random Forest A Random Forest classifier was then used to extrapolate the clustered soil classes to the whole study area based on the training sites and significant environmental parameters, which were identified in the previous step. The Random Forest algorithm works with classification trees, of which each makes a class prediction based on various predictor variables. The trees are created using bootstrapping, a technique which holds back parts of the available objects and uses random subsets to grow various decision trees for each class. The final classification decision for each pixel is based on aggregation of the predictions of all random variable trees [31,38]. Depending on the scaling of the output variable, Random Forest models distinguish between regression- and classification-trees. Since our outcome variable has a nominal scale with 4 values representing 4 soil classes, the classification-tree method was obtained using the standard setting of 500 random trees. Validation of the model is called OOB (Out-Of-Bag) and is based on the bootstrapping. The classification-trees of random subsets are used to predict values which were previously held back and show an error matrix of the model quality [38]. Furthermore, a variable importance plot shows the importance of the individual input variables [38]. For a smoother result, the modeled image was filtered using a $3 \times 3$ pixel majority filter. For more information on Random Forest modeling we refer to Lawrence et al. [39], Pal [40] and Breimann [38]. 


\section{Model Canopy Coverage}

Polygons (about $200 \mathrm{~m} \times 200 \mathrm{~m}$ ) were drawn over 52 of the 82 test sites. Using high resolution imagery (RapidEye from 27 December 2010), the crown-cover of all visible trees and large shrubs was painted black in a painting software at a scale of 1:1000 and a pencil size of $0.6 \mathrm{px}$. The output histogram of each polygon gave the exact value for the percentage of black within the image which corresponds with the canopy coverage in percent. This way, canopy cover in this study is defined by the whole area of woody objects, neglecting that a tree does not cover $100 \%$ of the ground. Also considering the spatial resolution of RapidEye $(5 \mathrm{~m})$, the actual cover may be lower than our modeling results. A model was then established using Landsat NDVI as the variable to explain canopy cover of the 52 training sites. The model was derived using the RMA regression method as suggested by [41]. In comparison to conventional linear regression models, the RMA method is more robust and can better handle sampling and measurements errors on both the $\mathrm{x}$ and $\mathrm{y}$ axis [41]. Since field work was carried out in February, no green grass and crop residues are left at this date and many of the woody vegetation keeps green leaves throughout the dry season, Landsat scenes of February were averaged (22 February 2002; 13 March 2003; 28 February 2007; 20 February 2010). The mean NDVI has a strong correlation with the painted canopy cover of the training sites $\left(R^{2}=0.81 ; p \leq 0.01\right)$. Woody cover was then extrapolated to the whole study area via Landsat mean NDVI and the derived regression coefficients. Even though the percentage of green leaves is low for some tree species (e.g., Acacia senegal, Pterocarpus lucens), the reflectance signal of the bare soil is still suppressed due to the ligneous biomass cover. For more information on the methodology see Larsson [41]. Using the different soil types as masks, valuable information and quantification regarding the woody coverage of soil classes and degraded unvegetated regions could be obtained. Data from parallel studies was used to identify seriously degraded areas [2,18]

\section{Results and Discussion}

\subsection{Soil Clustering Corresponds with Local Denotations}

Clustering generated four soil classes at the $20 \%$ cutting-level which can be clearly validated by the elbow criterion [29]. These correspond with the soil types Dek, Bowel, Dior and Bardial which were denoted by the local population and are described in detail in Section 2.1. In the following, the classes assigned by the soil clustering are used, as the demarcation in the field was not always clear. Bowel areas for example contain forested depressions or appear depression-like in Dior areas. However, their soil properties are more similar to Bowel than to a Dek, hence, they were included in the Bowel class and only heavy clayey sites were clustered as Dek. The Wolof names were applied to the corresponding clustered group. This way, each of the 84 plots obtained a value between 1 and 4 regarding its group.

\subsection{Soil Types Significantly Differ in Properties}

Soil properties differ between the 4 soil types. According to the FAO classification, Dior and Bardial are both Arenosols, Dek are hydromorphic soils (e.g., Vertisol) and Bowel regions are composed by Regosols [42]. 
Our results show that Dek sites are most clayey with a mean clay content of $26 \%$, followed by the Regosols with 9\%. Dior and Bardial Arenosols have an almost identical grain size distribution $(p \leq 0.05)$ with a high portion of sand (85\%) (see Figure 3). However, at a confidence level of $10 \%$ Bardial have a significantly higher clay-content than Dior (6\% compared to $5 \%$ ). The $\mathrm{pH}$-value differs significantly, too $(p \leq 0.05)$. With 5.44, Dior have a 0.7 unit lower $\mathrm{pH}$-value than Bardial (6.13). Linked to these differences are the lower base saturation and cation exchange capacity $\left(\mathrm{Ca}^{2+}, \mathrm{Mg}^{2+}\right.$ and $\left.\mathrm{K}^{+}\right)$on Dior (all significant at $5 \%$ ).

Figure 3. Grain size distribution of the 4 soil types. Note that Dior and Bardial have an almost identical distribution.

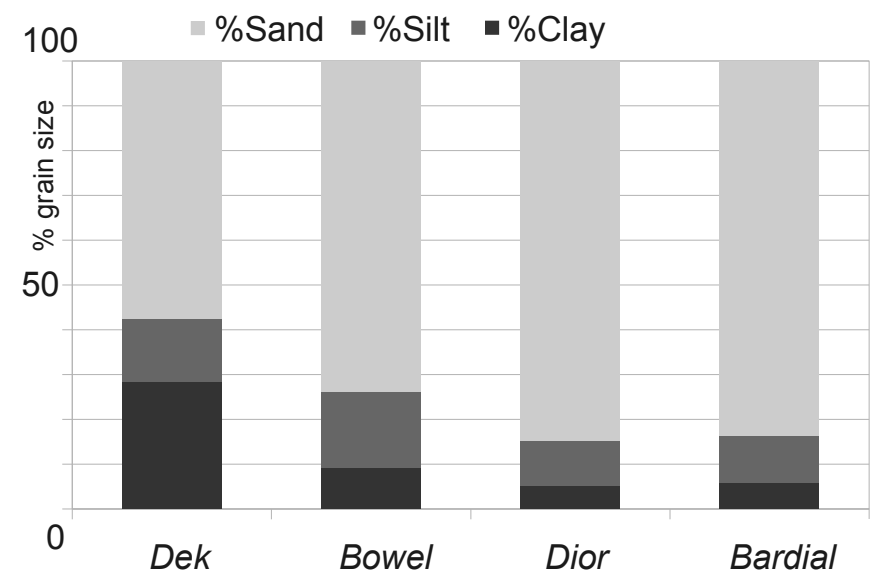

Mean organic carbon and humus are low (Dek) to very low (Bowel, Dior, Bardial) as are nitrogen and cation exchange capacity. Phosphate is rated within the lowest category for all soil types $(<1 \mathrm{mg} / \mathrm{kg})$, which is not surprising for tropical soils. Dek soils have the highest stability with 7.4, followed by Bowel Regosols (6.1) and both Arenosols (4.8 and 4.9). Available field capacity is high in the Regosols (22\%), medium in Dek (20\%) and low in Dior and Bardial Arenosols (9\%). For detailed information and further statistics on soil properties, see Table 2.

\subsection{Modeling Soil Types and Canopy Coverage}

\subsubsection{Soil Types}

The NMDS confirmed the results of the soil clustering by grouping the sites in the same manner (see Figure 4). Several significant predicting variables are identified. No evidence of a significant relationship between TRMM rainfall $\left(R^{2}=0.045\right) /$ northing $\left(R^{2}=0.06\right)$ and the soil properties can be verified at a confidence level of $10 \%$. Both variables point into opposite directions, indicating that rainfall considerably decreases further north. On the contrary, Landsat's bands $5\left(R^{2}=0.37\right), 7\left(R^{2}=0.42\right)$, as well as its TC brightness $\left(R^{2}=0.29\right)$ are highly significant $(p \leq 0.01)$ and point in the direction of the Arenosol sites Dior and Bardial, as does band $2\left(R^{2}=0.09 ; p \leq 0.05\right)$. This can be explained by the low woody coverage of these soils and therefore the high spectral reflectance of the soil properties. NDVI $\left(R^{2}=0.12\right)$, canopy cover $\left(R^{2}=0.24\right)$ and especially trees/ha $\left(R^{2}=0.48\right)$ are significant $(p \leq 0.05)$ and point in the direction of Dek and Bowel soils. Except from degraded sites, which are placed near 
the coordinate origin, these sites have a high vegetation density. In addition, significant $(p \leq 0.05)$ relationships between easting $\left(R^{2}=0.1\right) /$ altitude $\left(R^{2}=0.14\right)$ and the soil types are observed.

Table 2. Soil parameters classified according to the 4 clustered soil types derived from field and laboratory measurements. Mean value, range [min-max] and standard deviation are provided.

\begin{tabular}{lcccc}
\hline Parameter & Dek & Bowel & Dior & Bardial \\
\hline Samples n & 7 & 19 & 28 & 30 \\
$\mathrm{pH}\left(\mathrm{H}_{2} 0\right)$ & $\mathbf{5 . 7 3}[4.4-8] 1.35$ & $\mathbf{6 . 1 7}[5.3-8.1] 0.58$ & $\mathbf{5 . 4 4}[4.9-6.4] 0.33$ & $\mathbf{6 . 1 3}[5.3-7.4] 0.43$ \\
Humus $(\%)$ & $\mathbf{1 . 5 6}[1.14-1.9] 0.25$ & $\mathbf{0 . 6 2}[0.38-0.97] 0.21$ & $\mathbf{0 . 3 4}[0.19-0.44] 0.06$ & $\mathbf{0 . 3 9}[0.24-0.68] 0.1$ \\
$\mathrm{~N}(\%)$ & $\mathbf{0 . 1 4}[0.12-0.18] 0.02$ & $\mathbf{0 . 0 8}[0.05-0.11] 0.02$ & $\mathbf{0 . 0 6}[0.04-0.08] 0.01$ & $\mathbf{0 . 0 6}[0.04-0.09] 0.01$ \\
$\mathrm{CN}$ & $\mathbf{6 . 8}[5.4-8.1] 0.9$ & $\mathbf{4 . 5}[3-6] 0.9$ & $\mathbf{3 . 4}[1.6-5.8] 0.9$ & $\mathbf{3 . 7}[2.2-5.3] 0.8$ \\
$\mathrm{P}(\mathrm{mg} / \mathrm{kg})$ & $\mathbf{0 . 2 1}[0.1-0.5] 0.12$ & $\mathbf{0 . 2 2}[0.01-1.1] 0.28$ & $\mathbf{0 . 2 4}[0.04-0.62] 0.17$ & $\mathbf{0 . 4 8}[0.0-3.2] 0.71$ \\
$\mathrm{CECpot}(\mathrm{cmol} / \mathrm{kg})$ & $\mathbf{9 . 0 4}[5.3-21] 5.61$ & $\mathbf{2 . 5 6}[1.51-4.5] 0.8$ & $\mathbf{1 . 3 3}[1-1.9] 0.23$ & $\mathbf{2 . 0 5}[1.1-4.3] 0.84$ \\
$\mathrm{BS}(\%)$ & $\mathbf{9 7 . 8}[95.4-99.8] 1.71$ & $\mathbf{9 7 . 8}[95.5-99.6] 1.2$ & $\mathbf{9 2 . 7}[78.8-98] 3.75$ & $\mathbf{9 7 . 5}[95.2-99.6] 1.25$ \\
$\mathrm{Ca}(\mathrm{cmol} / \mathrm{kg})$ & $\mathbf{6 . 2 6}[2.75-15.87] 4.68$ & $\mathbf{1 . 6}[0.81-3.32] 0.67$ & $\mathbf{0 . 6 7}[0.4-1.1] 0.16$ & $\mathbf{1 . 2 2}[0.63-2.5] 0.5$ \\
$\mathrm{Mg}(\mathrm{cmol} / \mathrm{kg})$ & $\mathbf{1 . 8 3}[1.1-4.4] 1.16$ & $\mathbf{0 . 5 1}[0.25-0.83] 0.16$ & $\mathbf{0 . 2 4}[0.13-0.36] 0.05$ & $\mathbf{0 . 4 4}[0.2-1.08] 0.23$ \\
$\mathrm{~K}(\mathrm{cmol} / \mathrm{kg})$ & $\mathbf{0 . 5}[0.34-0.65] 0.11$ & $\mathbf{0 . 1 8}[0.09-0.27] 0.05$ & $\mathbf{0 . 1 2}[0.08-0.2] 0.03$ & $\mathbf{0 . 1 6}[0.06-0.28] 0.05$ \\
FC $(\% \mathrm{vol})$ & $\mathbf{1 9}$ & $\mathbf{2 2}$ & $\mathbf{8}$ & $\mathbf{8}$ \\
Sand $(\%)$ & $\mathbf{5 3}[32-65] 10$ & $\mathbf{7 1}[57-81] 7$ & $\mathbf{8 6}[79-92] 4$ & $\mathbf{8 5}[77-93] 4$ \\
Clay $(\%)$ & $\mathbf{2 6}[16-38] 7$ & $\mathbf{9}[4-20] 4$ & $\mathbf{5}[3-9] 1$ & $\mathbf{6}[3-10] 2$ \\
Stability $(3-8)$ & $\mathbf{7 . 4}[6-8] 0.8$ & $\mathbf{6 . 1}[5-8] 0.9$ & $\mathbf{4 . 8}[3-7] 1$ & $\mathbf{4 . 9}[3-7] 1.1$ \\
\hline
\end{tabular}

Figure 4. NMDS-ordination with grouped test sites (according to 28 soil parameters) and fitted variables. REF 2, 5, 7: Landsat reflectance June; TC: Tasseled Cap brightness; ALT: altitude; CAN-COV: canopy cover; TRMM: annual rainfall; LONG: longitude; LAT: latitude. The arrows show significant relationships between the soil samples and fitted variables by pointing into the respective direction. A longer arrow means a stronger relation.

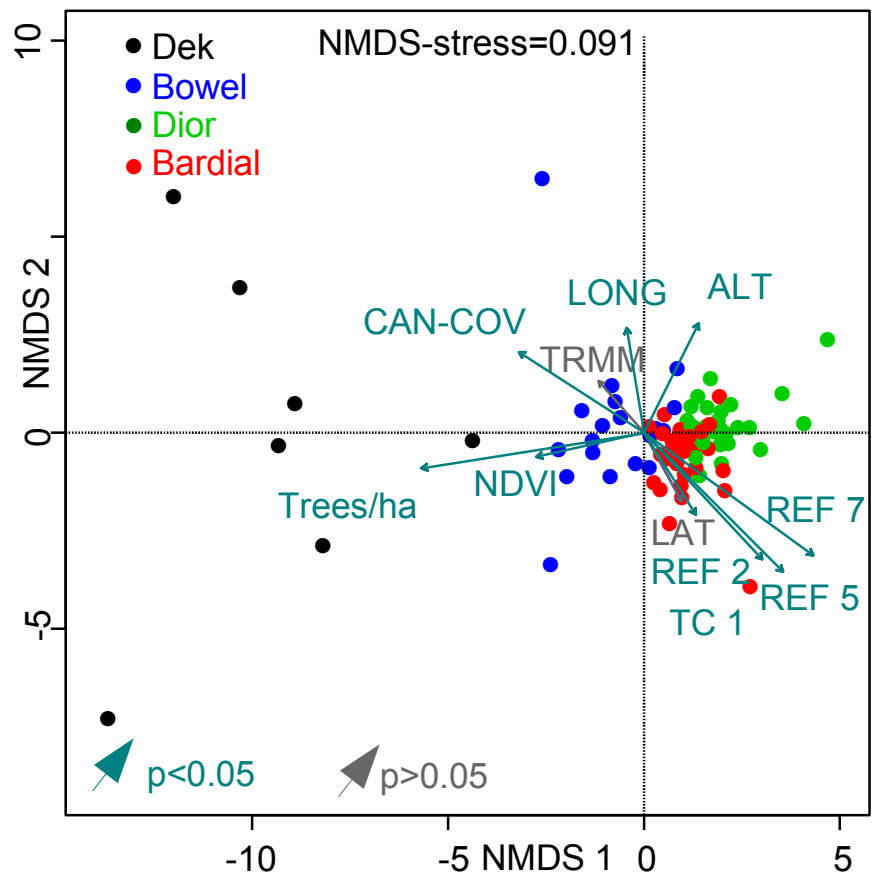


Figure 5 shows the result of the 4 soil types modeled with Random Forest via 84 test sites and 6 significant ( $p \leq 0.05$ ) variables (DEM; Landsat bands 2, 5, 7; TC brightness; NDVI). Despite being significant, easting was excluded from modeling because a visual comparison showed that including the variable causes a loss of important details. In contrast to the NMDS which uses values averaged over the test sites (about 2 ha), Random Forest works pixel-wise at a resolution of $30 \mathrm{~m}$. The model's variable importance plot identifies the DEM as the most important input parameter, followed by Landsat's bands 5 and 7 (see Figure A1). Canopy cover is the least important variable and therefore excluded in the modeling process. The OOB confusion matrix attests a high model quality with an error rate of $7.3 \%$ (see Table A3). Visual analysis revealed that several sparsely vegetated river beds of the Ferlo valley are erroneously modeled as Bowel due to similar soil- and spectral-properties. Ferruginous Bowel soils are largely located on the sandstone plateau in the east of the study area, but several spots are spread throughout the sandy zones, especially south of Khogue, but also west of Linguère and north of Kadji. They constitute the largest category in the study area with $39 \%$ while Dek are the smallest with a portion of 2\%. Dek are mainly situated inside and along recent and ancient river beds. Dior are the second predominant soil with a fraction of $31 \%$ equally distributed mainly along the northern and southern sandy ecoregion and sporadic along valleys in the east. Bardial soils are slightly less widespread (28\%) and often found more closely to river beds. This explains the slightly higher clay content.

Figure 5. Modeled soil types in the Ferlo around Linguère. The legend shows the soil names in Wolof. For the corresponding scientific names, see Table 1. The area represents the square in Figure 1.

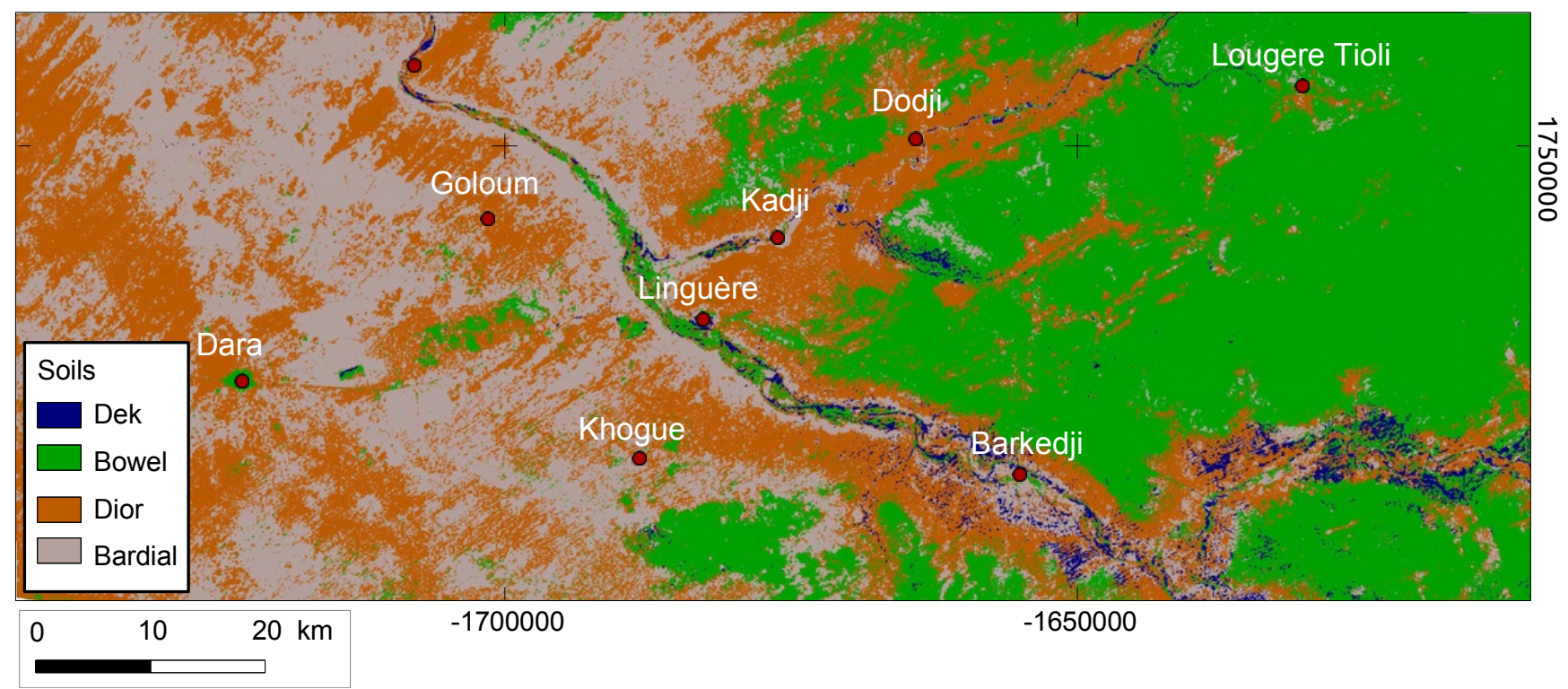

Validation of the modeled map was conducted by comparisons with existing soil maps. Neither the map of Maignien [15] nor the one of Stancioff et al. [16] distinguish between different Arenosols. Apart from that, the pattern and distribution of soil types in the modeled soil map show a good agreement with existing maps. Stancioff et al. [16] found 3 prevailing soils corresponding with our clustered classes: (1) hydromorphic soils are situated in river beds and ancient valleys (Dek/Xour areas); (2) Regosols are found in the east and agree with Bowel; (3) Sandy tropical ferruginous soils are located in the western part of the study area and agree with the distribution of Dior and Bardial Arenosols. Maignien [15] 
classified hydromorphic soils as weakly hydromorph sandy and clayey soils. In Maignien's soil map, the east of the study area (the Bowel region) is covered by weakly leached tropical ferruginous soils, characterized by solidification and crusts in the deep. Maignien [15] found two more soils in the zone modeled as Dior/Bardial: (1) ferruginous brown-red soils on siliceous sands situated around Kadji and in the northwest and west of the study area and (2) brown sub-arid soils, sometimes calcareous in the deep (south of Linguère).

By aggregating the modeled soil map to a coarser resolution (up to $1 \mathrm{~km}$ ), the spatial pattern is preserved and still provides information on the predominant soil. This indirectly gives information on predominant woody vegetation and potential usage at a coarse scale. Local land cover maps $[19,43]$ show a similar spatial pattern but the provided information differs. In comparison with MODIS (Moderate Resolution Imaging Spectroradiometer) global land cover maps, a much more realistic pattern can be observed on our soil map [29].

\subsubsection{Canopy Coverage}

Canopy coverage (Figure 6) obviously differs between the 4 soil types and will be discussed in detail in Section 3.4. It considerably decreases from west to east, indicating the geomorphological change from the sandy to the ferruginous Ferlo. Forested and deforested (i.e., degraded) areas are clearly visible in Figures 6 and 7.

Figure 6. Modeled canopy cover for the whole study area. The area represents the square in Figure 1.

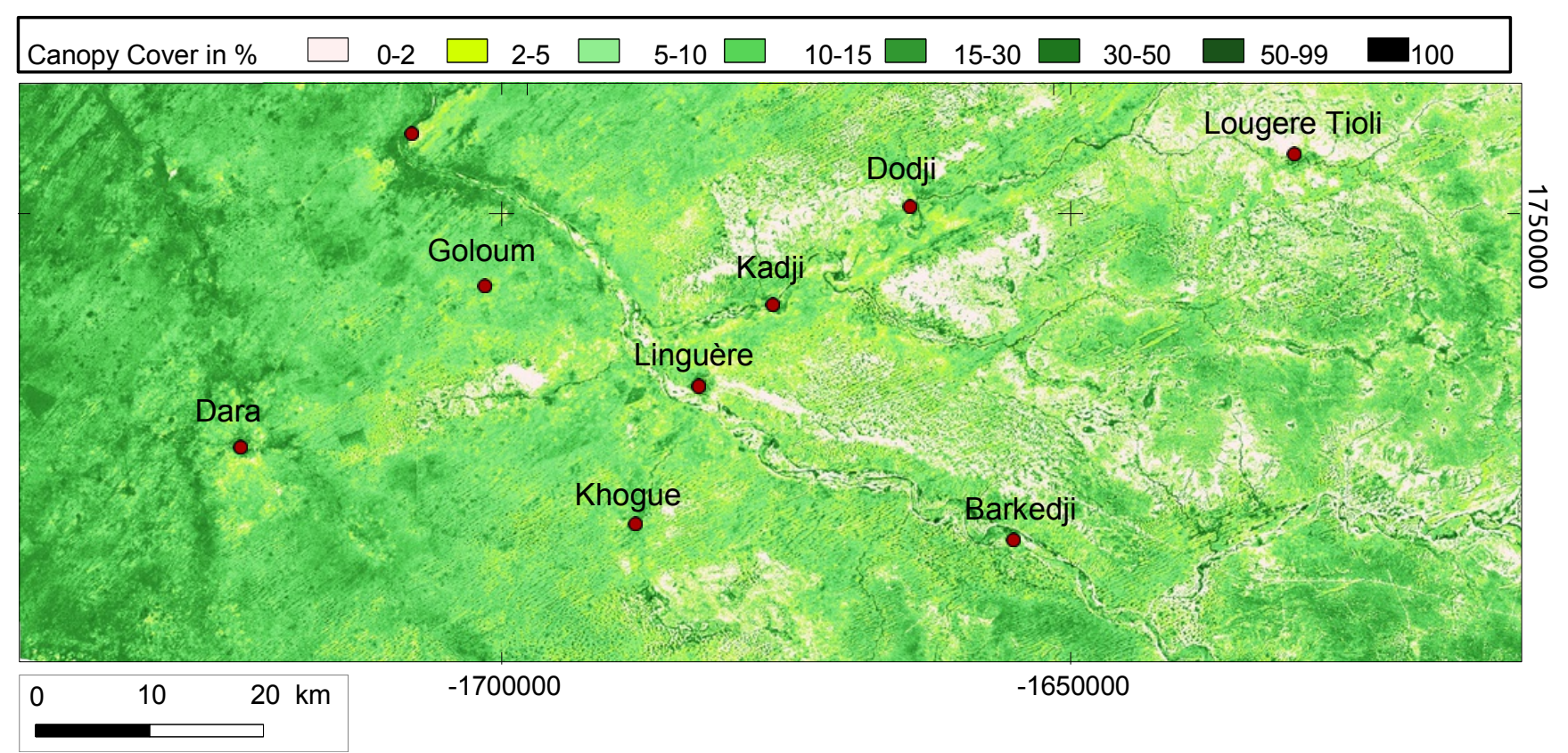


Figure 7. Woody cover (left) and soil types (right) around the Wolof villages Kadji and Kol Kol, north-east of Linguère. The Dior region with a sparse woody cover is mainly used for peanut cultivation while millet is grown on Bardial near the villages. Parts of the Bowel region are degraded and eroded with no woody vegetation left, as they are not suitable for cropping and thus serve as a source for fuel-wood. Dek are flooded during the rainy season.
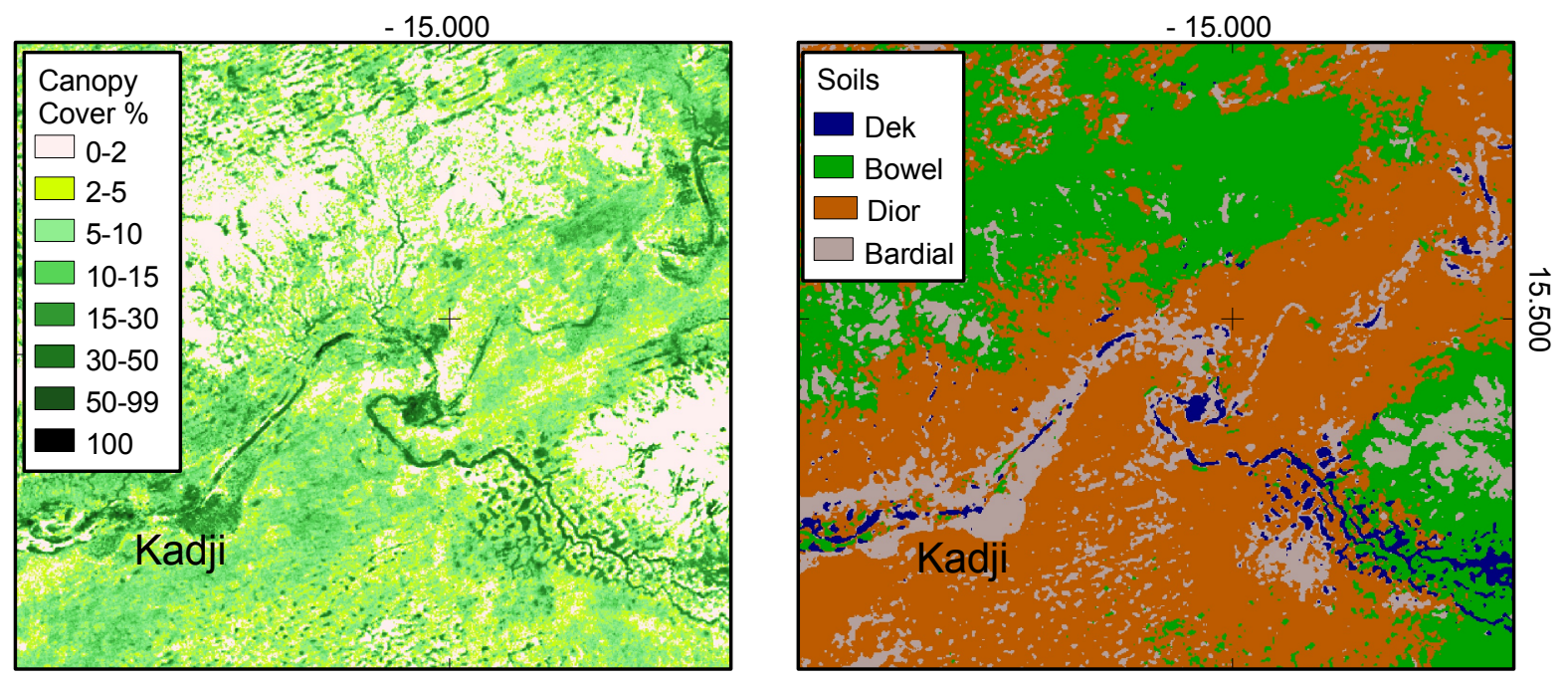

\subsubsection{Relationship between Soil and Woody Vegetation}

This section describes and discusses woody species surveys and canopy coverage according the classes (1) Dek; (2) Bowel; (3) Dior; and (4) Bardial. Results are summarized in Table 3 and Figure 8. Regarding species, trees and shrubs of all heights are included, whereas tree height, trunk circumference and trees/ha are only available for trees $>4 \mathrm{~m}$ (see Table 3 ). The ratio tree/shrub counts the relation between trees $>4 \mathrm{~m}$ and shrubs $<4 \mathrm{~m}$. At this point it has to be noted that much of today's woody species composition is strongly influenced by humans and livestock. However, a clear pattern can still be observed. Mostly dominating are Balanites aegyptiaca (43\%), Combretum glutinosum (15\%) and Acacia raddiana (15\%) while 21 other species account for $27 \%$.

Table 3. Mean vegetation parameters classified according to the 4 clustered soil types derived for test sites from field data $(*)$ and for the whole study area from remote sensing products.

\begin{tabular}{lcccc}
\hline Parameter & Dek & Bowel & Dior & Bardial \\
\hline \% Spatial occurrence & 2 & 38 & 31 & 29 \\
Altitude $(\mathrm{m})$ & 24 & 46 & 39 & 40 \\
NDVI (June) & 0.19 & 0.15 & 0.16 & 0.17 \\
Canopy cover $(\%)$ & 18 & 6 & 7 & 10 \\
Canopy cover $<1 \%(\%)$ & 0 & 29 & 9 & 3 \\
Trees/ha $(>4 \mathrm{~m}) *$ & 53 & 26 & 11 & 15 \\
Tree height $(>4 \mathrm{~m})(\mathrm{m}) *$ & 8 & 7.62 & 7.2 & 7.8 \\
Tree circumference $(>4 \mathrm{~m})(\mathrm{cm}) *$ & 70 & 34 & 59 & 63 \\
$\%$ Shrubs & 34 & 60 & 77 & 61 \\
\hline
\end{tabular}


Figure 8. Distribution of the predominant species according to the 84 test sites (all heights). Note that Balanites aegyptiaca is dominant in all classes. Other: Acacia nilotica var. adansonii, Acacia nilotica var. tomentosa, Acacia pennata, Adansonia digitata, Combretum aculeatum, Combretum nigricans, Commiphora africana, Bauhinia rufescens, Grewia bicolor, Piliostigma reticulatum, Sterculia setigera, Tamarindus indica, Ziziphus mauritiana.

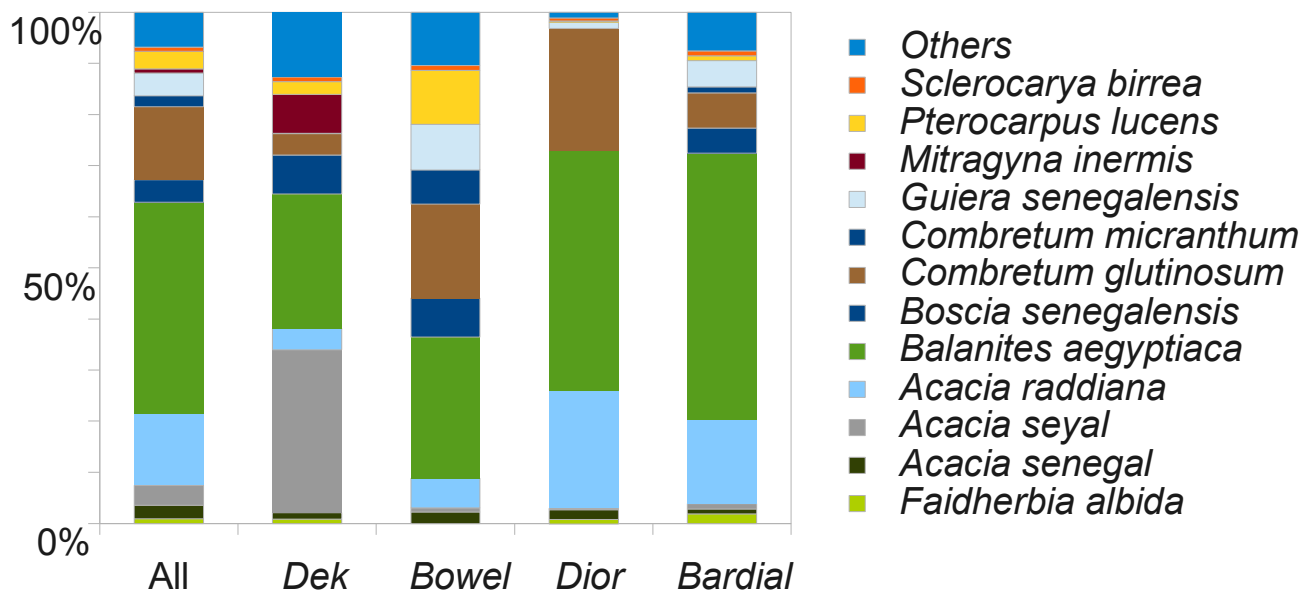

(1) A majority of rare species such as Mitragyna inermis and Acacia nilotica var. tomentosa are found on Dek soils and are mostly absent in other classes (see Figure 8). Especially the abundance of Acacia seyal is statistically significantly higher $(p \leq 0.05)$ on Dek than in all other classes. Also mean tree height and trunk circumference of trees are greatest for the Dek group. The ratio of shrubs to trees is $34 \%$, showing that large trees are more frequent on hydromorphic soils. Furthermore, trees/ha as well as mean canopy coverage outnumber all other classes. $87 \%$ of the classified Dek area exceeds a canopy cover of $10 \%$ (Table 3 ).

(2) As mentioned, it is not always easy to draw a strict boundary between a Dek soil within a Xour and a loamy Bowel. However, Bowel Regosols have a unique species composition with significantly higher portions of $P$. lucens, Guiera senegalensis, Combretum micranthum and Boscia senegalensis than the other classes $(p \leq 0.05)$. This composition follows the soil clustering, which generates only heavy clayey depressions with standing water as Dek and summarizes all lateritic and loamy sites including depressions (Xour) with above mentioned vegetation as Bowel. Species richness on Bowel Regosols is high (Figure 8). Woody cover ranges from $0 \%$ to $89 \%$ with a mean of $6 \%$ due to a very heterogeneous landscape (see Figure 7). $28 \%$ of the zone can be considered as relatively dense non-degraded bushland with a canopy cover $>10 \%$, and $55 \%$ exceed a canopy cover of $5 \%$. However, $29 \%$ of the Bowel soils are deforested, mostly a sign of degradation. Widespread degradation is mainly a problem of the Bowel class, as in all other soil classes combined, deforested areas account for merely $12 \%$. Shrubs or small trees $(<4 \mathrm{~m})$ constitute $60 \%$ of the woody vegetation, which is evidence for the prevailing shrub savanna (Table 3).

(3) Dior sites have a significantly higher abundance of $C$. glutinosum $(p \leq 0.05)$ than the other classes, most of them growing on peanut fallows and representing $24 \%$ of the woody population on Dior. Numbers in trees/ha, canopy cover, deforested areas and species diversity (Figure 8) are strongly influenced by humans, as most shrubs are cut down when a field is changed from fallow to actively cultivated cropland. Thus, coverage is higher on fallows but still low, since farmers prefer not 
to have any large trees within their groundnut fields, as trees attract birds which subsist on crops during the harvest. Trees are not needed for fixing nitrogen, as groundnuts and beans are legumes as well. This is also expressed by the percentage of shrubs and small trees $(<4 \mathrm{~m})$, which is $77 \%$ on Dior. Mean tree height and trunk circumference are slightly lower than on Bardial Arenosols which are used for growing millet (Table 3).

(4) Bardial exceed Dior in trees/ha and canopy cover as well. Deforested areas are mostly nonexistent on Bardial. Moreover, most B. aegyptiaca are found on Bardial soils, but their abundance is not significantly higher than on Dior (see Table 3 and Figure 8).

\subsection{Extensive Environmental Changes are Reported on all Soil Types}

Droughts, a general decrease in annual rainfall as well as human impact have taken a heavy toll on the woody vegetation in the Ferlo [1,2,8,17]. Tappan et al. [1] found a general decrease in mean tree cover from $10 \%-20 \%$ to $5 \%-15 \%$ within the past 50 years. Our data show that nowadays overall species diversity is low (Figure 8) and village elders in our study area report an overall woody species and tree cover decline due to more arid conditions. These statements are statistically confirmed by the studies of Herrmann and Tappan [5], Gonzalez et al. [7] and Gonzalez [6]. Our interviews reveal that the 4 modeled soil types react differently to dry periods and rainfall change. Moreover, human impact differs between the classes. In this section, environmental changes are described and discussed according the classes (1) Dek; (2) Bowel; (3) Dior; and (4) Bardial.

(1) Species richness and tree cover on clayey Dek is high, however, both are reported to have considerably declined in the past 50 years. In times of little rainfall, leaves of trees on Dek sites provide an important source of fodder throughout the dry season. These sites are exploited accordingly and often living trees are cut down to make leaves available to animals. Local people report that in combination with droughts and less rainfall, this has led to a strong decrease of large, old trees within Xour areas. Additionally, young trees struggle to survive due to massive numbers of animals who frequent the sites for drinking water, preventing rejuvenation.

(2) Most areas of lateritic Regosols (Bowel) belong to protected regions and are thus rarely used for cropping. Therefore, they were never cleared from bushland, although soil properties appear more fertile than those of Dior and Bardial Arenosols. However, the region is very heterogeneous, and often hard and impenetrable laterite is present near the surface. Local people and Tappan et al. [1] report that a poor infiltration rate and low water holding capacity make these areas vulnerable to droughts and little rainfall, leading to a decline or even local extinction of several species. E.g., Anogeissus leiocarpus, C. micranthum, Commiphora africana, Grewia bicolor, Sterculia setigera and Terminalia avicennioides are named to have strongly declined. The natural regeneration rate of other species (e.g., P. lucens, G. senegalensis) is good and significant greening trends are observed within this region, caused by an increment of the woody layer [22]. Elders report that 5 years after a drought the woody vegetation shows recovery under undisturbed conditions. In reality, over-exploitation by cutting, browsing and grazing as well as soil compaction by trampling leads to loss of vegetation and soil and hampers regeneration. Thus, a large figure of $29 \%$ of Bowel areas can be identified as deforested on our canopy cover map (Table 3 and Figure 7). As observed by 
Brandt et al. [2] and Tappan et al. [1], these patches used to be covered by dense woody vegetation 50 years ago and are now eroded barren land. This is particularly the case in close proximity to villages, roads, boreholes and along fossil valleys.

(3+4) According to interviewees, large parts of the natural vegetation on Dior and Bardial Arenosols were cleared by humans in the 20th century for the purpose of cropping and grazing. Areas formerly covered by dense and sometimes inaccessible bushland dominated by G. senegalensis and inhabited by wild animals were cleared. Only large trees or favored species (e.g., Faidherbia albida, A. nilotica, Acacia sieberiana, A. leiocarpus, Combretum nigricans, Lannea acida, S. setigera, T. avicennioides, Ziziphus mauritiana) were not felled. However, most of them exist only in very small numbers today (see Figure 8). Despite Arenosols having a large water storage capacity, which tempers the effects of dry years, some native species did not tolerate a general decrease in annual rainfall. Thus, local people report that the droughts in the 1970s and 1980s represent the starting point of a rapid increase of tree dying. Although a greening is observed which is caused by the woody layer [22], several species, which, according to village elders and older literature [13], were originally typical for this region and its soils, have now vanished (e.g., T. avicennioides). They have been replaced by three prevailing species (A. raddiana, B. aegyptiaca, C. glutinosum) which account for a share of over $90 \%$ on our Dior and Bardial test sites (see Figure 8). Although F. albida is a favored species and reported as being manifold on fields in former times, very few of these species larger than $4 \mathrm{~m}$ were found on Arenosols in 2012. However, various seedlings have been planted on cropland to reestablish F. albida, Z. mauritiana and other useful species as well as thousands of $A$. senegal on huge tree plantations. However, the seedlings are vulnerable to extreme events and livestock and are not able to grow without protection. Villages like Nguith (3 km west of Linguère) and Goloum have their own fenced areas where trees are planted and protected (Figure A2). Only villagers from the corresponding village are allowed to enter and practice sustainable farming.

\subsection{Environmental Management Depends on Soil Types}

Environmental management in Sahelian ecosystems face the brunt of optimization of scarce resources, which strongly vary between ecosystems and depend on local practices that change over time and space. A leading principle in land resources management is an accurate assessment and mapping of existing supply sources, and how these change over time and livelihood contexts. Our detailed soil and woody cover maps may contribute to a better understanding of the current situation in the Ferlo. In the study area, what we stratified as Bowel, is a vast grazing land of minor asset value for farmers and herders as compared to Dior and Bardial soils. In Bowel areas, dead trees can be legally collected in authorized areas, helping tree populations to regenerate elsewhere. These trees are the main source of firewood, but are also an important income source with growing urban demand. In reality, also living trees are cut in these areas, enforcing degradation. Thus, the extent of degradation in Bowel regions should be worrisome enough to cause concern. However, tolerating the encroaching degradation in Bowel regions is also a reasonable management decision, which helps to reduce the pressure on valuable sandy soils with much higher agricultural potential. Moreover, favoring more arid woody species might mitigate effects of future dry periods, as these species are robust, withstand droughts and grazing, and provide 
benefits to humans and the ecosystem even in dry times. Hence, the observed shift in biodiversity is not exclusively negative. Additionally, reforestations on Dior with drought resistant species help to generate income for the local people and stabilize the sandy soil to reduce erosion. These tree plantations can be clearly located on woody cover maps, which may also help to qualify the current state of the ecosystem and quantify the local degree of deforestation.

\section{Conclusions}

In this study, we highlighted the importance of soil properties in the context of ecosystem resilience and environmental change. Native Wolof soil names (Dek, Bowel, Dior, Bardial) were used to classify soils and to statistically establish relationships between soil types and woody vegetation. Results were successfully modeled for a region in the Sahel and provide a soil map which corresponds well with existing maps. We thus demonstrated that local knowledge can be well combined with scientific classifications, offering a concise and clear map. Using public Earth observation data, the map is easy to reproduce in remote regions of the African Sahel, where no detailed maps are available. Soil sampling and analysis, which both can be cumbersome tasks, is not necessary, as local knowledge of spatial units provides all required information and can be well extrapolated to a larger region. Combined with a high spatial resolution $(30 \mathrm{~m})$, the map offers an easy usability and provides quantitative information on species distribution, potential land usage and vulnerability to degradation. Additionally, this study assessed the spatial degree of deforestation by modeling woody cover at a $30 \mathrm{~m}$ resolution.

Interviews with village elders revealed extensive environmental changes and a massive decline of woody species within the past 40 years with major differences between the modeled soil types. Droughts and a decrease in annual rainfall are reported to have led to a local extinction of several species on Dior and Bardial (e.g., T. avicennioides), just as human activities and livestock grazing contributed to a transformation of land cover from bushland to an open tree and shrub savannah. Our tree survey showed that nowadays few robust species (B. aegyptiaca, C. glutinosum and A. raddiana) make up approximately $80 \%$ of all surveyed trees and shrubs. Due to its poor agricultural potential, the bushland has not been cleared in Bowel regions, however, our canopy cover map identified patches of deforested and degraded land, restricted to the Bowel area (29\%). This demonstrates that vegetation change (i.e., degradation and greening), resilience to climatic stress and human activities significantly depend on soil properties, and spatial heterogeneity is an important aspect when dealing with environmental changes in the Sahel.

\section{Acknowledgments}

This research is part of the $\mathrm{BMBF}$ (German Ministry of Education and Research) funded project micle which aims to explain linkages between migration, climate and environment. The first thank goes to our guides and translators in the field: Mohammed Lecor, Modou Gueye and Mitsuharu Uchiyama. We also thank our Senegalese colleagues at the CSE (Centre de Suivi Ecologique) in Dakar, namely Moussa Sall, Abdoul Aziz Diouf, Jacque André Ndione and Abdoulaye Wélé. Most processing was done using Open Source software (especially GRASS, R), therefore we thank the OSGEO community for providing free and powerful software packages. Finally we thank Regina Fleischanderl, Raphael Spiekermann and the anonymous referees for improving the paper, as well the DLR and the RESA program for providing RapidEye imagery. 


\section{Author Contributions}

The conception of the research approach and development of the methods was done by Martin Brandt, Tobias Grau and Cyrus Samimi. The data was collected and prepared by Tobias Grau (soil sampling, soil analyses, statistical soil analyses) and Martin Brandt (remote sensing and modeling, vegetation survey and interviews). The research was conducted by Martin Brandt and Tobias Grau. Analysis and interpretation was done by Martin Brandt and Tobias Grau and discussed with all authors. The manuscript was written by Martin Brandt with contributions from all authors.

\section{Conflicts of Interest}

The authors declare no conflict of interest.

\section{Appendix}

Table A1. All 28 soil parameters used for clustering and NMDS ordination are listed in this table.

\begin{tabular}{lc}
\hline & Variable \\
\hline $\mathrm{pH}$ & $\mathrm{pH}$-value $\left(\mathrm{H}_{2} 0\right)$ \\
$\mathrm{EC}$ & Slectrical conductivity $(\mu \mathrm{S} / \mathrm{cm})$ \\
$\mathrm{S}$ & Silt in $(\%)$ \\
$\mathrm{U}$ & Clay in $(\%)$ \\
$\mathrm{T}$ & Nitrate in $(\mathrm{mg} / \mathrm{kg})$ \\
$\mathrm{NO}^{3-}$ & Ammonium in $(\mathrm{mg} / \mathrm{kg})$ \\
$\mathrm{NH}^{4+}$ & Carbon $-\mathrm{Nitrogen} \mathrm{ratio}$ \\
$\mathrm{C} / \mathrm{N}$ & Nitrogen in $(\% \mathrm{matter})$ \\
$\mathrm{N}$ & carbon in $(\% \mathrm{matter})$ \\
$\mathrm{C}$ & sulfur in $(\% \mathrm{matter})$ \\
$\mathrm{S}$ & hydrogenf in $(\% \mathrm{matter})$ \\
$\mathrm{H}$ & calcium in $(\mathrm{cmol} / \mathrm{kg})$ \\
$\mathrm{Ca}^{2+}$ & magnesium in $(\mathrm{cmol} / \mathrm{kg})$ \\
$\mathrm{Mg}^{2+}$ & natrium in $(\mathrm{cmol} / \mathrm{kg})$ \\
$\mathrm{Na}^{+}$ & potassium in $(\mathrm{cmol} / \mathrm{kg})$ \\
$\mathrm{K}^{+}$ & aluminium in $(\mathrm{cmol} / \mathrm{kg})$ \\
$\mathrm{Al}^{3+}$ & iron in $(\mathrm{cmol} / \mathrm{kg})$ \\
$\mathrm{Fe}^{3+}$ & density in $\left(\mathrm{g} / \mathrm{cm}{ }^{3}\right)$ \\
$\mathrm{density}^{3+}$ & coarse sand in $(\%)$ \\
$\mathrm{WcMax}_{\mathrm{Humus}}$ & maximum water holding capacity in $(\%)$ \\
$\mathrm{CECpot}^{3+}$ & potential cation exchange capacity in $(\mathrm{cmol} / \mathrm{kg})$ \\
$\mathrm{BS}_{\mathrm{STA}}$ & base saturation in $(\%)$ \\
$\mathrm{CS}^{2}$ & soil stability \\
\hline &
\end{tabular}


Table A1. Cont.

\begin{tabular}{lc}
\hline & Variable \\
\hline MS & medium sand in $(\%)$ \\
FS & fine sand in $(\%)$ \\
\hline
\end{tabular}

Table A2. All remote sensing parameters fitted over the NMDS ordination are listed in this table. Parameters marked with $*$ have been used for Random Forest modeling.

\begin{tabular}{lc}
\hline Parameter & $R^{2}$ \\
\hline Trees/ha & 0.46 \\
Landsat Reflectance band 7 (REF 7) * & 0.42 \\
Landsat Reflectance band 5 (REF 5) * & 0.37 \\
Landsat Tasseled Cap Brightness (TC 1) * & 0.29 \\
Canopy cover (CAN COV) & 0.24 \\
DEM (SRTM) Altitude (ALT) * & 0.14 \\
Landsat NDVI * & 0.12 \\
Longitude (LONG) & 0.1 \\
Landsat Reflectance band 2 (REF2) * & 0.09 \\
Latitude (LAT) & 0.06 \\
TRMM annual rainfall & 0.045 \\
\hline
\end{tabular}

Figure A1. This figure identifies the most important predicting variables in the Random Forest model. Canopy cover was excluded in the modeling process as the least important predictor.

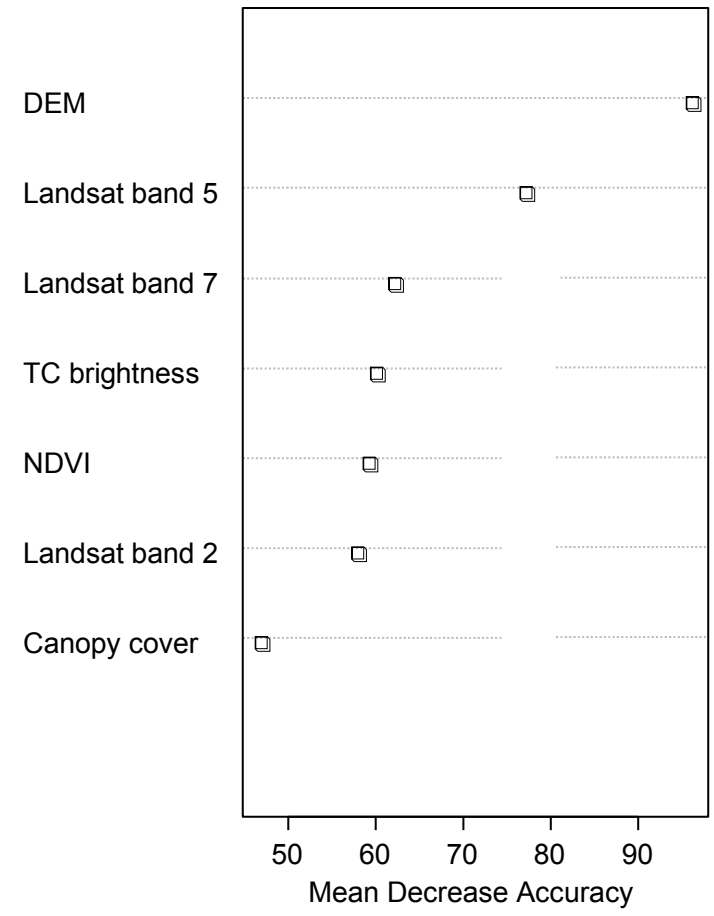


Table A3. This confusion matrix of the Random Forest model shows which pixels are correctly classified for each class. OOB (out-of-bag) estimate of error rate is $7.3 \%$ and attests a high model accuracy.

\begin{tabular}{lccccc}
\hline & Dek & Bardial & Dior & Bowel & Class error \\
\hline Dek & 71 & 0 & 4 & 3 & 0.0897 \\
Bardial & 2 & 851 & 54 & 14 & 0.0760 \\
Dior & 0 & 35 & 743 & 9 & 0.0559 \\
Bowel & 0 & 21 & 17 & 355 & 0.0966 \\
\hline
\end{tabular}

Figure A2. In this detail map of canopy cover west of Linguère two things are striking: (a) the degraded area in the west; and (b) the densely vegetated area south-west of Nguith which is a fenced area with planted trees. Herders and livestock need a permission to enter and only villagers cultivate few crops inside. Both photos are taken in September 2012.

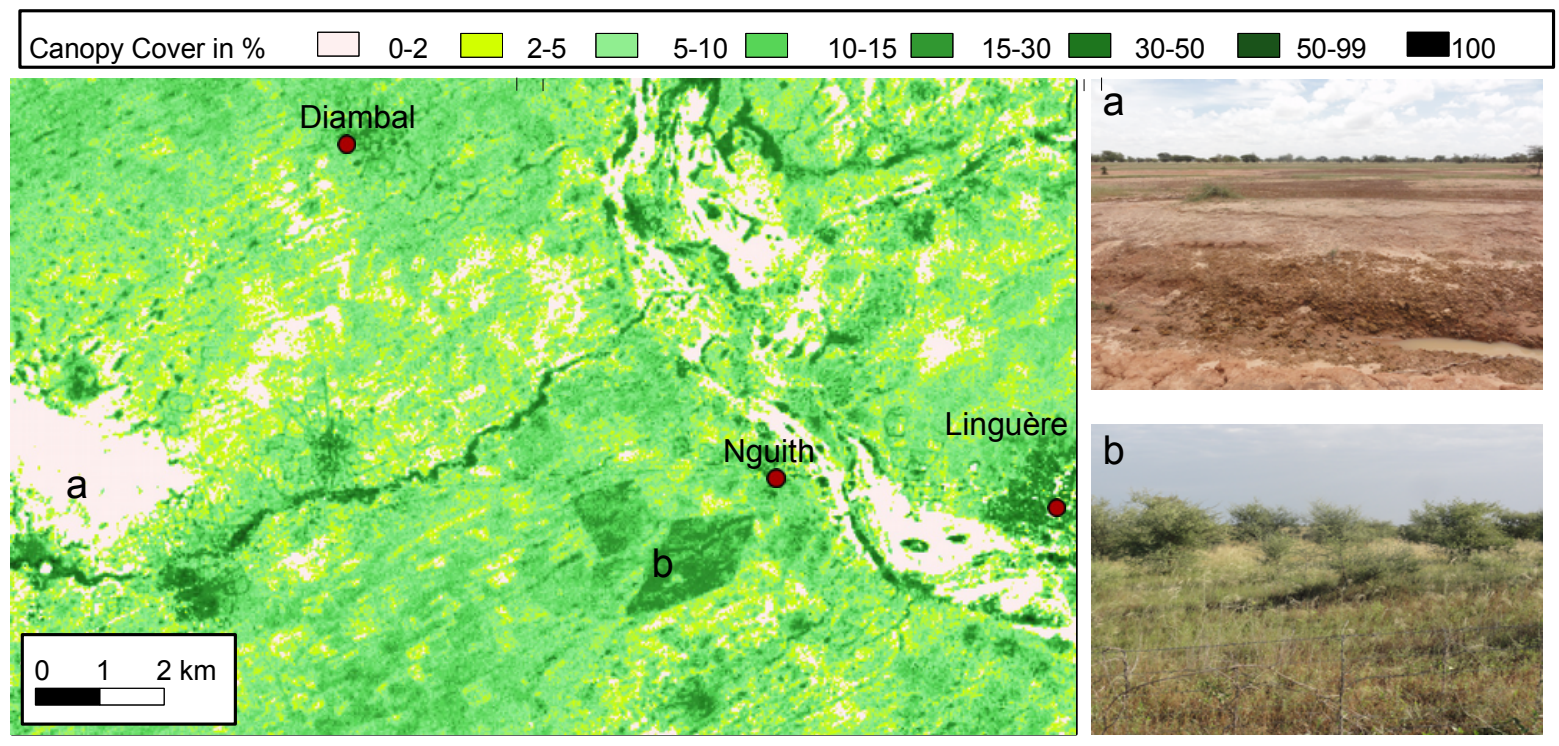

\section{References}

1. Tappan, G.; Sall, M.; Wood, E.; Cushing, M. Ecoregions and land cover trends in Senegal. J. Arid Environ. 2004, 59, 427-462.

2. Brandt, M.; Romankiewicz, C.; Spiekermann, R.; Samimi, C. Environmental change in time series-An interdisciplinary study in the Sahel of Mali and Senegal. J. Arid Environ. 2014, 105, $52-63$.

3. Reenberg, A.; Maman, I.; Bouzou Moussa, I.; Fog, B. Land saturation in SE Niger: Triangulating qualitative and quantitative information for critical assessment of land use trajectories. Land 2013, 2, 508-533.

4. Ali, A.; Lebel, T. The Sahelian standardized rainfall index revisited. Int. J. Climatol. 2009, $29,1705-1714$. 
5. Herrmann, S.; Tappan, G. Vegetation impoverishment despite greening: A case study from central Senegal. J. Arid Environ. 2013, 90, 55-66.

6. Gonzalez, P. Desertification and a shift of forest species in the West African Sahel. Clim. Res. 2001, 17, 217-228.

7. Gonzalez, P.; Tucker, C.; Sy, H. Tree density and species decline in the African Sahel attributable to climate. J. Arid Environ. 2012, 78, 55-64.

8. Vincke, C.; Diédhiou, I.; Grouzis, M. Long term dynamics and structure of woody vegetation in the Ferlo (Senegal). J. Arid Environ. 2010, 74, 268-276.

9. Herrmann, S.; Hutchinson, C. The changing contexts of the desertification debate. J. Arid Environ. 2005, 63, 538-555.

10. Ndour, T. La Degradation des sols au Sénégal: l'Exemple de deux Communautés Rurales. Ph.D. Thesis, Université Cheikh Anta Diop, Dakar, Senegal, 2001.

11. Maydell, H.J.V. Trees and Shrubs of the Sahel: Their Characteristics and Uses; Verlag Josef Margraf: Weikersheim, Germany, 1990.

12. Lawesson, J.E. Sahelian woody vegetation in Sénégal. Vegetatio 1990, 86, 161-174.

13. Adam, J. Généralités sur la flore et la vegetation du Senegal = Études Sénégalaises $N^{\circ} 9$. Connaissance du Sénégal Fascicule III: Climat-Sols-Végétation; Centre de Recherches et de Documentation du Sénégal: Saint-Louis, Senegal, 1965.

14. Charreau, C.; Fauck, R. Les sols du Senegal = Études Sénégalaises $N^{\circ} 9$. Connaissance du Sénégal Fascicule III: Climat-Sols-Végétation; Centre de Recherches et de Documentation du Sénégal: Saint-Louis, Senegal, 1965.

15. Maignien, R. Carte pédologique du Sénégal; Office de la Recherche Scientifique et Technique Outre-Mer: Dakar-Hann, Senegal, 1965.

16. Stancioff, A.S. Cartographie et Teledetection des Ressources de la Republique du Senegal; Remote Sensing Institute, South Dakota State University: Brookings, SD, USA, 1986.

17. Miehe, S.; Kluge, J.; von Wehrden, H.; Retzer, V. Long-term degradation of Sahelian rangeland detected by 27 years of field study in Senegal. J. Appl. Ecol. 2010, 47, 692-700.

18. Centre de Suivi Ecologique (CSE). Evaluation Locale de la Degradation des Terres-Rapport G.A.A. de Barkedji; Technical Report PR 41683; CSE: Dakar, Senegal, 2009.

19. ROSELT. La Surveillance Environnementale dans L'observatoire ROSELT/OSS du Ferlo; Rapport scientifique 2003-2005; Centre de Suivi Ecologique: Dakar, Senegal, 2005.

20. Strommer, G.; Brandt, M.; Diongue-Niang, A.; Samimi, C. Analysis of daily rainfall of the Sahelian weather-station Linguère (Senegal)_-Trends and its impacts on the local population. In Proceedings of the EGU General Assembly Conference Abstracts, Vienna, Austria, 7-12 April 2013; Volume 15, p. 12716.

21. Diouf, A.; Lambin, E.F. Monitoring land-cover changes in semi-arid regions: Remote sensing data and field observations in the Ferlo, Senegal. J. Arid Environ. 2001, 48, 129-148.

22. Brandt, M.; Verger, A.; Diouf, A.A.; Baret, F.; Samimi, C. Local vegetation trends in the Sahel of Mali and Senegal using long time series FAPAR satellite products and field measurement (1982-2010). Remote Sens. 2014, 6, 2408-2434. 
23. Duvall, C.S. Classifying physical geographic features: The case of Maninka farmers in southwestern Mali. Geogr. Ann.: Ser. B Hum. Geogr. 2008, 90, 327-348.

24. Ndiaye, M. Systemes de Production et Mutations des Paysages Ruraux dans la Basse Vallee du Ferlo au Senegal. Ph.D. Thesis, Université de Bordeaux III, Bordeaux, France, 2007.

25. Herrick, J.E.; Jornada Experimental Range. Monitoring Manual for Grassland, Shrubland, and Savanna Ecosystems; USDA-ARS Jordana Experimental Range; University of Arizona Press: Las Cruces, NM, USA/Tucson, AZ, USA, 2005.

26. Stocking, M.A.; Murnaghan, N. A Handbook for the Field Assessment of Land Degradation; Routledge: New York, NY, USA, 2001.

27. Sponagel, H.; Ad-hoc-Arbeitsgruppe Boden der staatlichen geologischen Dienste und der Bundesanstalt für Geowissenschaften und Rohstoffe. In Bodenkundliche Kartieranleitung: Mit 103 Tabellen; Schweizerbart: Stuttgart, Germany, 2005; p. 473.

28. Blume, H.P.; Stahr, K.; Leinweber, P. Bodenkundliches Praktikum: Eine Einführung in Pedologisches Arbeiten für Ökologen, Land- und Forstwirte, Geo- und Umweltwissenschaftler; Spektrum Akademischer Verlag: Heidelberg, Germany, 2010.

29. Grau, T. Die Bodenqualität in der Ferlo-Region (Senegal) in Abhängigkeit von den Raum-und Nutzungsparametern. Master's Thesis, University of Vienna, Vienna, Austria, 2013.

30. Landon, J.R.; Booker Agriculture International Limited. Booker Tropical Soil Manual: A Handbook for Soil Survey and Agricultural Land Evaluation in the Tropics and Subtropics; Routledge: New York, NY, USA, 1991.

31. Brenning, A. Benchmarking classifiers to optimally integrate terrain analysis and multispectral remote sensing in automatic rock glacier detection. Remote Sens. Environ. 2009, 113, 239-247.

32. Ward, J.H. Hierarchical grouping to optimize an objective function. J. Am. Stat. Assoc. 1963, 58, 236-244.

33. Borg, I.; Groenen, P.J.F. Modern Multidimensional Scaling: Theory and Applications; Springer: New York, NY, USA, 2007.

34. Duvall, C.S. Biocomplexity from the ground up: Vegetation patterns in a West African savanna landscape. Ann. Assoc. Am. Geogr. 2011, 101, 497-522.

35. Huffman, G.J.; Bolvin, D.T.; Nelkin, E.J.; Wolff, D.B.; Adler, R.F.; Gu, G.; Hong, Y.; Bowman, K.P.; Stocker, E.F. The TRMM Multisatellite Precipitation Analysis (TMPA): Quasi-global, multiyear, combined-sensor precipitation estimates at fine scales. J. Hydrometeorol. 2007, 8, 38-55.

36. Hildebrandt, G. Fernerkundung und Luftbildmessung: für Forstwirtschaft, Vegetationskartierung und Landschaftsökologie; Wichmann: Heidelberg, Germany, 1996.

37. Kauth, R.J.; Thomas, G.S. The tasselled cap-A graphic description of the spectral-temporal development of agricultural crops as seen by Landsat. In Proceedings of the Symposium on Machine Processing of Remotely Sensed Data, West Lafayette, IN, USA, June 29-July 11976; p. 159.

38. Breiman, L. Random Forests. Mach. Learn. 2001, 45, 5-32.

39. Lawrence, R.L.; Wood, S.D.; Sheley, R.L. Mapping invasive plants using hyperspectral imagery and Breiman Cutler classifications (randomForest). Remote Sens. Environ. 2006, 100, 356-362. 
40. Pal, M. Random forest classifier for remote sensing classification. Int. J. Remote Sens. 2005, 26, 217-222.

41. Larsson, H. Linear regressions for canopy cover estimation in Acacia woodlands using Landsat-TM, -MSS and SPOT HRV XS data. Int. J. Remote Sens. 1993, 14, 2129-2136.

42. Food \& Agriculture Organization (FAO). Guidelines for Soil Description; FAO: Rome, Italy, 2006.

43. Sarr, M.A. Cartographie des changements de l'occupation du sol entre 1990 et 2002 dans le nord du Sénégal (Ferlo) à partir des images Landsat. Cybergeo: Eur. J. Geogr. 2009, 472, 1-38.

(C) 2014 by the authors; licensee MDPI, Basel, Switzerland. This article is an open access article distributed under the terms and conditions of the Creative Commons Attribution license (http://creativecommons.org/licenses/by/3.0/). 